\title{
INCIDENTAL THYROID CANCER IN A SUBCENTIMETRIC NODULE WITH BENIGNE ULTRASOUND CRITERIA IN A PATIENT WITH GRAVES DISEASE
}

Enalda Demaj,Endri Ahmetaj,Marjeta Kermaj,Violeta Hoxha, Gerond Husi,Thanas Fureraj,Dorina Ylli,Agron Ylli

Service of Endocrinology,University Center Hospital “Mother Theresa”,Tirana ,Albania

\section{INTRODUCTION}

A thyroid nodule discovered in a patient with Graves disease(GD) should be evaluated and managed according to guidelines .A

subcentimeter incidental thyroid cancer founded in a patients with

GD, without high-risk history, without suspicious sonographic(US) features has not been reported yet.

\section{CLINICAL CASE}

A 40 year-old female patient,presented to our hospital with symptoms of thyrotoxicosis. On physical examination heart rate was $120 \mathrm{bpm}$, blood pressure of $130 / 90 \mathrm{mmHg}$, with a nontender thyroid gland,with murmurs on auscultation, without nodules on palpation. No exophtalmos or skin changes were noted .The patient was under treatment with Methimazole $5 \mathrm{mg}$ twice daily and beta blocker, since seven months.Labaratory Investigations showed AST:93I/1,ALT: $156 \mathrm{U} / 1(\mathrm{~N}:<40 \mathrm{U} / \mathrm{m})$. Thyroid function tests revealed freeT3:22.52pg/ml $(\mathrm{N}: 2-$

4.4),free $\mathrm{T} 4: 63.04 \mathrm{ng} / \mathrm{dl}(\mathrm{N}: 10.6-19.4)$ and

TSH:0.003uUI/ml(N:0.35-4.94).TRAbs: 1.8

$\mathrm{UI} / \mathrm{ml}(\mathrm{N}<1)$.A thyroid ultrasound detected a diffuse enlargement with diffuse hypervascularity of thyroid,with a hyperechoic rounded nodule measuring $9 \mathrm{~m} \div 6.4 \mathrm{~mm}$ in the left lobe(with regular borders, with halo,without microcalcifications) and a hypoechoic right lobe.A scintigraphy showed a increased diffuse uptake,suggestive of GD.Fine needle aspiration biopsy(FNAB) was not performed. Our patient underwent a total thyroidectomy after two months, in a euthyroid state.Histopatological examination of the thyroid gland showed a focus of papillary microcarcinoma,follicular variant, lying into the nodule detected on US.

\section{CONCLUSIONS}

Thyroid cancer occurs in GD patients with a frequency of $2 \%$ or less. We refered a case of incidental thyroid cancer in a Graves disease with no malignant ultrasound features. We conclude that the presence of benign nodules on ultrasonographic examination does not reduce the risk of malignancy. We recommend a FNAB in all nodules detected on ultrasound in Graves disease and early total thyroidectomy in these cases.

KEYWORDS:Graves ¿disease, Thyroid Cancer,Fine Needle Aspiration Biopsy 